\title{
Morphogenesis of Poliovirus
}

\section{Existence of Particles Sedimenting at $150 \mathrm{~S}$ and Having the Properties of Provirion}

\author{
NAOMI GUTTMAN' ${ }^{1}$ AND DAVID BALTIMORE* \\ Department of Biology and Center for Cancer Research, Massachusetts Institute of Technology, Cambridge, \\ Massachusetts 02139
}

Received for publication 1 February 1977

\begin{abstract}
An apparent precursor to the poliovirion that cosediments with the virion at $150 \mathrm{~S}$ was identified by its content of VP-0. It has properties previously associated with the provirion, a structure that sedimented at $125 \mathrm{~S}$, and it may be an alternate form of provirion. Like virions, the $150 \mathrm{~S}$ precursor binds to and elutes from cells, after which it sediments at about $125 \mathrm{~S}$.
\end{abstract}

A series of structures have been isolated that are thought to be intermediates in the maturation pathway of virions of picornaviruses (12). These putative intermediates include the initial translation product, a 100,000 -dalton polyprotein $(7,13)$; the cleavage products of the polyprotein (VP-0, VP-1, and VP-3); aggregates of VP-0, VP-1, and VP-3 that sediment at 14S and are thought to be pentamers (11); a complete protein shell sedimenting at $74 \mathrm{~S}$, consisting of 60 copies each of VP-0, VP-1, and VP-3 and called procapsid $(8,11)$; and, finally, a particle, called provirion, that has viral RNA plus the procapsid proteins (5). The final step of morphogenesis appears to be the cleavage of VP-0 to VP-2 plus VP-4; this cleavage transforms a provirion into a virion.

In our previous studies of provirion, we characterized it as sedimenting at about 125S (more slowly than the $150 \mathrm{~S}$ virions), containing RNase-resistant RNA, and being dependent on the presence of $\mathrm{Mg}^{2+}$ for its stability (5). Provirion was also disrupted by sodium dodecyl sulfate (SDS) under conditions that did not disrupt virions. In vitro incubations of cytoplasmic extracts appeared to allow provirion, but not virions, to form (6).

Recent attempts to continue investigation of provirion have been stymied by our inability to find $125 \mathrm{~S}$ particles with the properties of provirion. Characterization of the $150 \mathrm{~S}$ virion band in sucrose gradients, however, revealed that material with the properties of provirion could be found admixed with virions. Apparently, some still-undefined aspects of our previous studies allowed the particle to sediment more slowly. We report here the characterization of

\footnotetext{
${ }^{1}$ Present address: Department of Virology, The Hebrew University, Hadassah Medical School, Jerusalem, Israel.
}

the particles sedimenting at $150 \mathrm{~S}$ and further studies on their nature.

\section{MATERIALS AND METHODS}

The growth of suspended HeLa cells, their infection by Mahoney type 1 poliovirus in the presence of $5 \mu \mathrm{g}$ of actinomycin D per $\mathrm{ml}$, and the analysis of virus-related particles by means of sucrose gradient centrifugation have been described previously $(2,8)$. The labeling of poliovirus-infected HeLa cells with $\left[{ }^{35} \mathrm{~S}\right] \mathrm{methionine}$ and the preparation and analysis of cytoplasmic extracts were performed as described previously (5).

The analysis of proteins by polyacrylamide gel electrophoresis was a modification of the Tris-glycine-buffered system described by Maizel (10). Protein samples were disrupted by boiling in the presence of SDS plus 0.07 M 2-mercaptoethanol and were subjected to electrophoresis through an SDS-polyacrylamide linear gradient slab gel. After electrophoresis, the gel was dried and analyzed by autoradiography or fluorography (3), followed by scanning of the film and automatic integration with a Canalco model $\mathrm{G}$ microdensitometer.

$\left.{ }^{[35} \mathrm{S}\right]$ methionine (100 to $400 \mathrm{Ci} / \mathrm{mmol}$ ) was purchased from New England Nuclear Corp. Actinomycin D was a gift from Merck Sharp and Dohme.

\section{RESULTS}

Provirion was originally observed by labeling poliovirus-infected HeLa cells according to a protocol designed to enrich for newly made virions (5). More recently, when the particles found in cells labeled for $30 \mathrm{~min}$ were analyzed by sedimentation through a 15 to $30 \%$ sucrose gradient containing $1.5 \mathrm{mM} \mathrm{Mg}^{2+}$ (Fig. 1), only peaks in the $150 \mathrm{~S}$ virion region and in the $73 \mathrm{~S}$ procapsid region were observed. There was no peak of radioactivity between the virions and procapsids that might correspond to the previously described provirion. 
To further characterize the structures found in the cytoplasmic extract, a portion of each fraction of the sucrose gradient was analyzed by electrophoresis through a 10 to $20 \%$ SDS-polyacrylamide gradient slab gel, and the protein bands were located by autoradiography (Fig. $1 \mathrm{~A}$; each gel slot corresponds to the sucrose gradient fraction with which it is aligned). The virion region of the gradient contained primarily VP-0, VP-1, VP-2, VP-3, and high-molecular-weight material corresponding to noncapsid virus protein 2 (NCVP-2). The procapsid region was enriched in VP-0, VP-1, and VP-3 and contained larger proteins. Proteins that remained at the top of this gradient included the majority of NCVP-X and NCVP-1, as well as some NCVP-2, NCVP-4, and VP-0, VP-1, and VP-3.

The presence of so much VP-0 in the $150 \mathrm{~S}$ virion peak suggested that immature virions could be sedimenting with mature particles, and the distribution of VP-0 in the gradient implied that the protein was not simply present as a procapsid contaminant. The virion fractions containing VP-0 also contained VP-2, so that virion and potential provirion particles were not resolved.

To further characterize the $150 \mathrm{~S}$ material enriched in VP-0, 150S particles were isolated from a gradient similar to the one described and were divided into three portions prior to sedimentation. One portion was exposed to EDTA and sedimented through an EDTA-containing gradient to determine whether the particles required $\mathrm{Mg}^{2+}$ for stability. The second portion received SDS, and the third portion remained in the presence of $\mathrm{Mg}^{2+}$. The major peak in each gradient was at $150 \mathrm{~S}$, while the EDTA-containing gradient contained a small amount of $73 \mathrm{~S}$ material. After sedimentation, the percentage of VP- 0 present in the $150 \mathrm{~S}$ peak relative to the other virion proteins was reduced even in the presence of $\mathrm{Mg}^{2+}$ (Table 1).

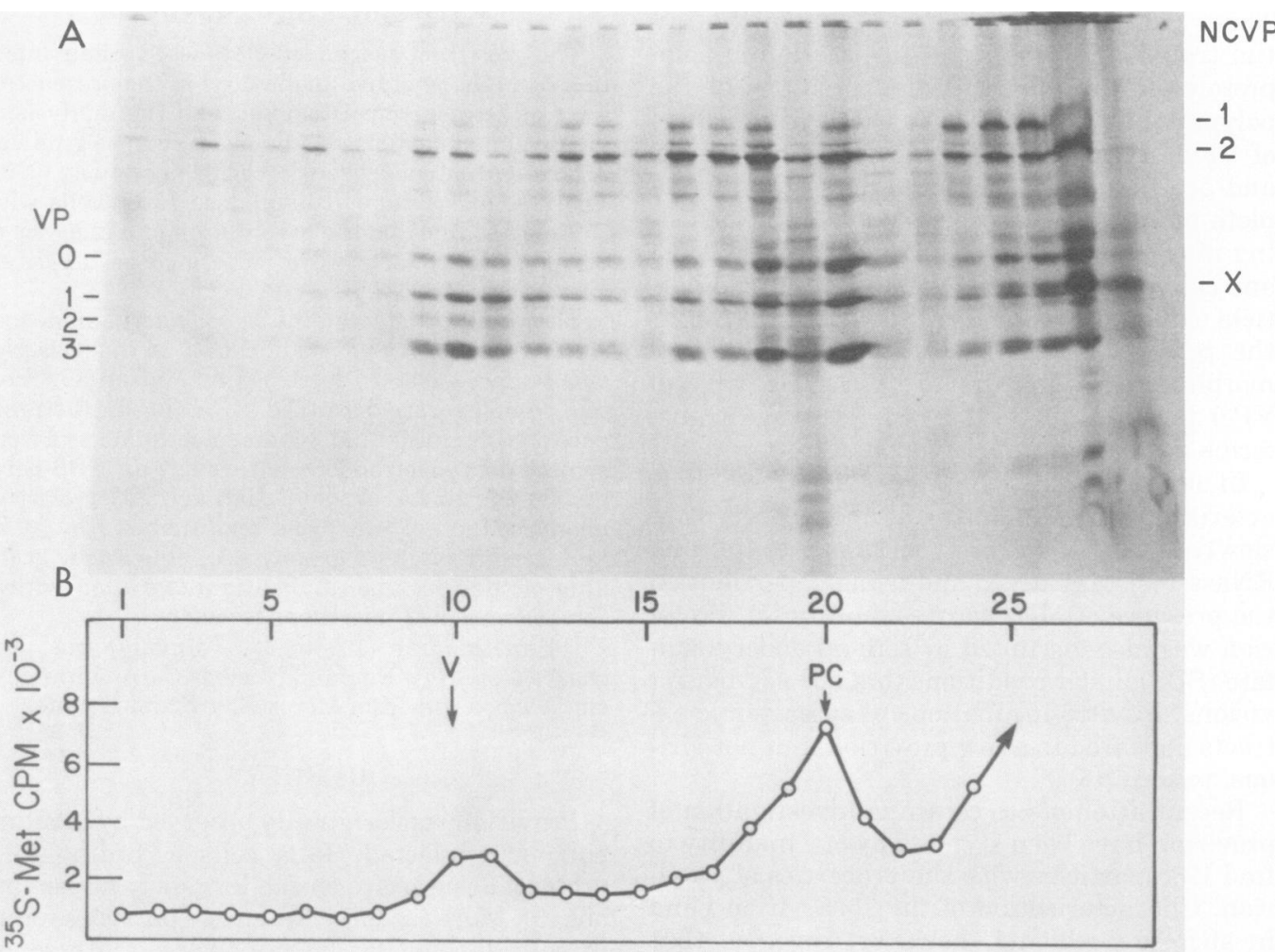

Fig. 1. Sucrose gradient profile of labeled, infected HeLa cell extract. Poliovirus-infected HeLa cells $(4 \times$ $10^{7}$ in $10 \mathrm{ml}$ of Earle saline) were labeled for $25 \mathrm{~min}$ at $3 \mathrm{~h}$ postinfection with $16 \mu \mathrm{Ci}$ of $\left.{ }^{35} \mathrm{~S}\right]$ methionine per $\mathrm{ml}$, followed by a chase with excess unlabeled methionine for 5 min. The infected cells were exposed to $1 \%$ Nonidet $P-40$; the nuclei were removed by centrifugation, and the post-nuclear supernatant was sedimented through a 15 to $30 \%$ sucrose gradient in RSB. Fractions were collected, and the trichloroacetic acid-insoluble radioactivity was determined $(B)$. Each sample was then concentrated by trichloroacetic acid precipitation, and the samples were subjected to electrophoresis in parallel on a 10 to $20 \%$ SDS-polyacrylamide gradient slab gel. The autoradiogram of the gel is illustrated, and each slot corresponds to a gradient fraction. Electrophoresis was from top to bottom (A). 
TABLE 1. Distribution of radioactivity among the virion proteins ${ }^{a}$

\begin{tabular}{lrrrr}
\hline \multirow{2}{*}{ Determination } & \multicolumn{4}{c}{ \% recovered as: } \\
\cline { 2 - 5 } & VP-0 & VP-1 & VP-2 & VP-3 \\
\hline 150S, original & 19.6 & 23.6 & 15.6 & 41.1 \\
$150 \mathrm{~S},+\mathrm{Mg}^{2+}$ & 7.0 & 17.8 & 20.9 & 54.1 \\
$150 \mathrm{~S},-\mathrm{Mg}^{2+}$ & 2.8 & 15.5 & 22.8 & 57.6 \\
150S, +SDS & 3.1 & 20.9 & 23.0 & 52.3 \\
Top of SDS gra- & 23.2 & 22.9 & 7.1 & 34.8 \\
dient & & & & \\
\hline
\end{tabular}

${ }^{a}$ A poliovirus-infected, ${ }^{[35}$ S $]$ methionine-labeled HeLa cell cytoplasmic extract was prepared and sedimented through RSB-sucrose, as described in the legend to Fig. 1. The 150S material (original) was divided into three portions. One portion was diluted with RSB $\left(+\mathrm{Mg}^{2+}\right)$, and a second portion was exposed to $0.5 \%$ SDS (+SDS); both were sedimented through RSB-sucrose gradients. A third portion received $20 \mathrm{mM}$ EDTA $\left(-\mathrm{Mg}^{2+}\right)$ and was sedimented through a sucrose gradient prepared in NEB (10 mM Tris [pH 7.4], $10 \mathrm{mM} \mathrm{NaCl}$, and $20 \mathrm{mM}$ EDTA). The indicated regions of the gradients were analyzed for their polypeptide composition by electrophoresis on a 10 to $20 \%$ SDS-polyacrylamide gradient slab gel. The relative radioactivity in each protein was determined by automatic integration of the autoradiogram.

Sedimentation after exposure to EDTA or SDS reduced the fraction of VP- 0 twofold relative to the particles maintained in $\mathbf{M g}^{2+}$. These results showed that some of the $150 \mathrm{~S}$ material was unstable upon resedimentation and that particles enriched in VP-0 were less stable in EDTA or SDS than in the presence of $\mathrm{Mg}^{2+}$. This is in agreement with the earlier findings that provirion was unstable in SDS or EDTA (5).

To establish whether the 150S particles enriched in VP-0 were precursors to more mature particles, a pulse-chase experiment was performed. Poliovirus-infected HeLa cells were labeled with $\left[{ }^{35} \mathrm{~S}\right]$ methionine for $30 \mathrm{~min}$ at $3 \mathrm{~h}$ postinfection, followed by the addition of excess cold methionine and guanidine to prevent the formation of virions $(1,5)$. Cytoplasmic extracts made at different times thereafter were sedimented through $\mathrm{Mg}^{2+}$-containing sucrose gradients; the $150 \mathrm{~S}$ virion peak was located, and the particles were then serially treated with EDTA and SDS. From each sample, the 150S particles treated in different ways were analyzed for their polypeptide content by SDS-polyacrylamide slab gel electrophoresis. The relative radioactivity of each virion protein was determined by integrating the densitometer scan of the autoradiogram of the gels, and the amount of VP-0 in each sample relative to the sum of the virion proteins was determined (Fig. 2). After $30 \mathrm{~min}$, the VP-0 present in the $150 \mathrm{~S}$ peak decreased with time in the presence of guanidine, while the amount of radioactivity in virions remained constant. There was an increase in the amount of radioactivity in the procapsid during this time, in agreement with earlier findings (8). The EDTA and SDS treatments reduced the amount of VP-0 in the virion peak to a level of 1 to $3 \%$. The above results

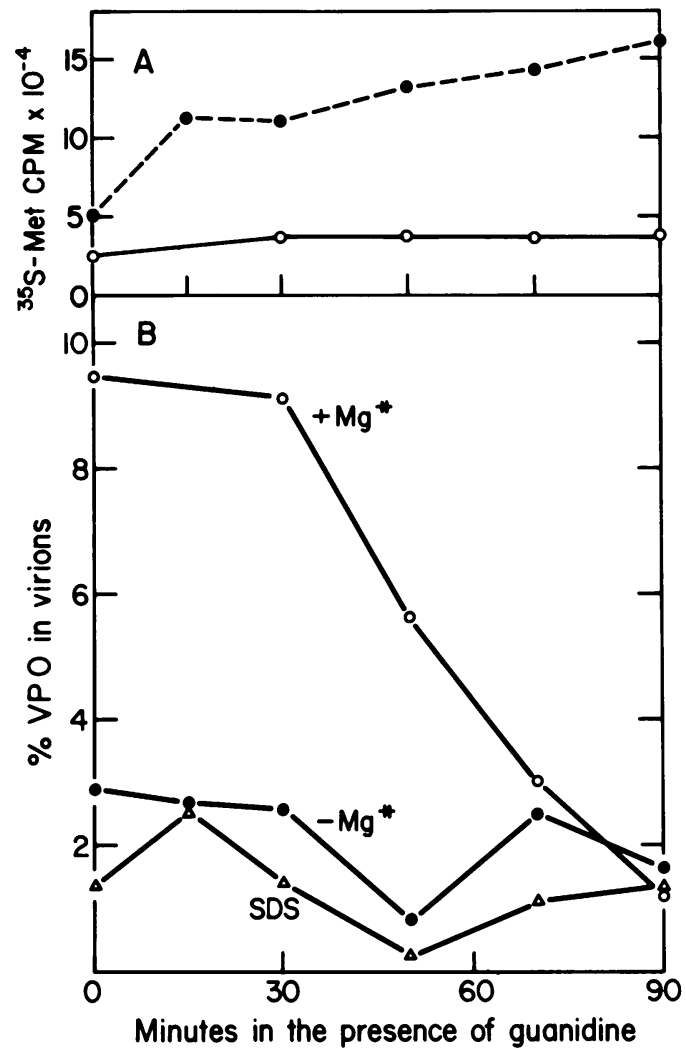

FIG. 2. Maturation of virion in the presence of guanidine. Poliovirus-infected HeLa cells were labeled as described in the legend to Fig. 1. After 30 min of labeling with $\left[{ }^{35} \mathrm{~S}\right]$ methionine, the cells were placed in growth medium containing $0.1 \mathrm{mM}$ methionine and $2 \mathrm{mM}$ guanidine. There was no further incorporation of radioactivity during the chase. Samples were removed at the indicated times after the addition of guanidine, and cytoplasmic extracts were prepared and sedimented through 15 to $30 \%$ sucrose gradients in $R S B\left(+M^{2+}\right)$. The $150 S$ regions from the gradients were exposed to $20 \mathrm{mM}$ EDTA and sedimented through 15 to $30 \%$ sucrose in NEB (see footnote a of Table 1) gradients $\left(-\mathrm{Mg}^{2+}\right)$. The $150 \mathrm{~S}$ peaks were isolated, exposed to $0.5 \%$ SDS, and sedimented through 15 to $30 \%$ sucrose in $0.5 \%$ SDS-0.1 M NaCl-0.01 M Tris (pH 7.5)-0.001 M EDTA for 2.5 $h$ at 27,000 rpm in a Beckman SW27 rotor at $22^{\circ} \mathrm{C}$. The radioactivity in the gradients was determined by scintillation counting. The protein content of the peaks was determined by electrophoresis on a 10 to $20 \%$ SDS-polyacrylamide gradient slab gel, followed by fluorography and densitometry. (A) Radioactivity in the procapsid (O) and virion (O) peaks of the $\mathrm{Mg}^{2+}$ gradients. (B) VP-O content of the $150 S$ region from each gradient, expressed as a percentage of the radioactivity in the sum of the virion proteins. 
confirmed the finding that much of the VP-0 was present in relatively unstable particles that sedimented with virions. Furthermore, since poliovirions were allowed to mature in the infected cells, the relative quantity of VP-0 in $150 \mathrm{~S}$ particles decreased with time, while the total radioactivity in the $150 \mathrm{~S}$ peak remained constant. It is probable, therefore, that the particles enriched in VP-0 are indeed precursors to mature virions.

An attempt was made to separate the immature particles from the mature particles by binding the $150 \mathrm{~S}$ material to HeLa cells. Poliovirions bind reversibly to cells at $22^{\circ} \mathrm{C}$ and can be eluted from the cells in an altered form by incubation at $37^{\circ} \mathrm{C}(4,9)$. In contrast, procapsids from virus-infected cells do not bind. It was of interest to determine whether the immature particles would behave as virions or procapsids. The 150S material isolated as described above was exposed to $\mathrm{HeLa}$ cells for $60 \mathrm{~min}$ at $22^{\circ} \mathrm{C}$ in growth medium. The unbound particles were separated from the cell-associated material, and the bound material was eluted by incubation at $37^{\circ} \mathrm{C}$ for $20 \mathrm{~min}$. The unbound and eluted particles were analyzed by sedimentation through RSB ( $10 \mathrm{mM} \mathrm{NaCl}, 10 \mathrm{mM}$ Tris-hydrochloride [pH 7.35], $1.5 \mathrm{mM}$ magnesium chloride)-sucrose gradients, followed by an examination of the polypeptide composition of the particles by polyacrylamide gel electrophoresis (Fig. 3). The unbound particles sedimented at $150 \mathrm{~S}$. The eluted particles sedimented at $130 \mathrm{~S}$, like the eluted particles from mature virions. VP-4 was released from the eluted particles, but it was still associated with the unbound particles. This is in agreement with the finding that $130 \mathrm{~S}$ particles generated from mature virions have lost VP-4 (N. Guttman, Ph.D. thesis, Massachusetts Institute of Technology, Cambridge, 1976). Note that the VP-4 region of the gel is contaminated with several protein species slightly larger than VP-4. These species appear to be minor degradation products of other viral proteins and can be resolved from VP-4 by the high-resolution gradient gel system used here (Guttman, Ph.D. thesis; 12). The bound and eluted particles contained as much VP-0 as did the unbound particles. The less mature particles were thus able to bind to cells and elute in an altered form along with more mature particles.

\section{DISCUSSION}

Although we were unable to find the $125 \mathrm{~S}$ provirion in the experiments reported here, we found particles sedimenting at $150 \mathrm{~S}$ that have the properties originally ascribed to provirion: they have VP-0, they are disrupted by EDTA, and they are disrupted by SDS. Because the particles with VP-0 sediment with the virions, it is not possible to say if they have any VP-2 or not. By analogy with our previous finding that the 125S provirion lacks VP-2, we believe that under our present conditions a distinct $150 \mathrm{~S}$ provirion containing no VP-2 may exist, but it is also possible that all of the $150 \mathrm{~S}$ particles have undergone some cleavage of VP-0 to VP-2 plus VP-4. The enrichment of VP-0 relative to VP-2 in the SDS-sensitive fraction of 150 S particles (Table 1, last line) suggests that structures with little VP-2 are the ones sensitive to SDS.

Why could we find $125 \mathrm{~S}$ provirion previously but not in the present experiments? No concrete answer is available, but a change of laboratory facilities occurred at the time the $125 \mathrm{~S}$ provirion could no longer be isolated. It could be that an inadvertent component in the cell growth medium or the reagents used has changed; a change in the source of water used is a possible explanation. It is widely observed that picornavirus particles can exist in two
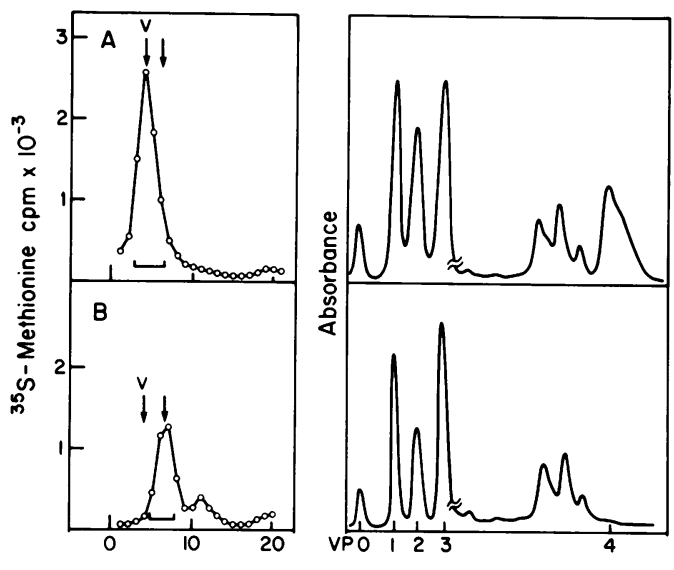

Fraction number

Distance migrated $\rightarrow$

Fig. 3. Cell-mediated alteration of immature virions. $A\left[{ }^{35} \mathrm{~S}\right]$ methionine-labeled, infected-cell extract was prepared as described in the legend of Fig. 1. The $150 S$ particles were isolated from an RSB sucrose gradient and exposed to $\mathrm{HeLa}$ cells for $60 \mathrm{~min}$ at room temperature in growth medium. The cells were washed, and the unbound material was saved (A). The virus-cell complexes were placed at $37^{\circ} \mathrm{C}$ for $20 \mathrm{~min}$. The cells were removed by sedimentation, and the eluted particles were analyzed $(B)$. The unbound and eluted particles were analyzed in parallel by sedimentation through RSB-sucrose, and the polypeptide components of the peaks were determined by electrophoresis on a 10 to $18.5 \%$ SDS-polyacrylamide gradient gel. Illustrated (left to right) are the $R S B$-sucrose gradient profiles, the gel scans of VP-O3 , and, on a separate scale, the gel scans of the VP-4 region. 
states that differ in sedimentation rate (12). It is likely that our previous conditions favored the slow-sedimenting state, whereas our present conditions favor the $150 \mathrm{~S}$ state. Under our present conditions we have also been unable to show in vitro provirion synthesis as was previously described (6).

Our present evidence still supports a model of poliovirion morphogenesis in which RNA associates with procapsid, and only then does the final cleavage occur, generating VP-2 plus VP-4 from VP- 0 . The particles containing VP-0 appear already able to bind to cells and undergo the transition to altered particles mediated by the receptor complex on the surface of sensitive cells. During this transition, virions lose VP-4, but VP-0, like VP-2, is maintained. It is not possible to know if the VP-0-containing particles are infectious. The $125 \mathrm{~S}$ provirions were not infectious and quite possibly could not bind to cells. They may have represented the altered form of the 150S, VP-0-containing particles.

\section{ACKNOWLEDGMENTS}

This work was supported by Public Health Service grant AI08388 from the National Institute of Allergy and Infectious Diseases and grants CA 12174 and CA 14051 from the National Cancer Institute.

D. B. is a Research Professor of the American Cancer Society.

\section{LITERATURE CITED}

1. Baltimore, D. 1969. The replication of picornaviruses, p. 101-176. In H. B. Levy (ed.), The biochemistry of viruses. Marcel Dekker, New York.
2. Baltimore, D., M. Girard, and J. E. Darnell. 1966 . Aspects of the synthesis of poliovirus RNA and the formation of viral particles. Virology 29:179-189.

3. Bonner, W. M., and R. A. Laskey. 1974. A film detection method for tritium-labeled proteins and nucleic acids in polyacrylamide gels. Eur. J. Biochem. 46:8388.

4. Fenwick, M. L., and P. D. Cooper. 1962. Early interactions between poliovirus and ERK cells. Some observations on the nature and significance of the rejected particles. Virology 18:212-223.

5. Fernandez-Tomas, C. B., and D. Baltimore. 1973. Morphogenesis of poliovirus. II. Demonstration of a new intermediate, the provirion. J. Virol. 12:1122-1130.

6. Fernandez-Tomas, C. B., N. Guttman, and D. Baltimore. 1973. Morphogenesis of poliovirus. III. Formation of provirion in cell-free extracts. J. Virol. 12:1181-1183.

7. Jacobson, M. F., and D. Baltimore. 1968. Polypeptide cleavages in the formation of poliovirus proteins. Proc. Natl. Acad. Sci. U.S.A. 61:77-84.

8. Jacobson, M. F., and D. Baltimore. 1968. Morphogenesis of poliovirus. I. Association of the viral RNA with coat protein. J. Mol. Biol. 33:369-378.

9. Joklik, W. K., and J. E. Darnell. 1961. The adsorption and early fate of purified poliovirus in HeLa cells. Virology 13:439-447.

10. Maizel, J. V., Jr. 1971. Polyacrylamide gel electrophoresis of viral proteins, p. 179-246. In K. Maramorosch and $H$. Koprowski (ed.), Methods in virology, vol. 5. Academic Press Inc., New York.

11. Phillips, B. A., D. F. Summers, and J. V. Maizel, Jr. 1968. In vitro assembly of poliovirus-related particles. Virology 35:216-226.

12. Rueckert, R. R. 1976. On the structure and morphogenesis of picornaviruses, p. 131-132. In H. FraenkelConrat and R. R. Wagner (ed.), Comprehensive virology, vol. 6. Plenum Press, New York.

13. Summers, D. F., J. V. Maizel, and J. E. Darnell. 1965. Evidence for virus-specific non-capsid proteins in poliovirus-infected HeLa cells. Proc. Natl. Acad. Sci. U.S.A. 54:505-513. 